\title{
ИНВЕСТИЦИОННОЕ ОБЕСПЕЧЕНИЕ РАЗВИТИЯ СОЦИАЛЬНО ОРИЕНТИРОВАННОЙ ИНФРАСТРУКТУРЫ РЕГИОНА
}

В современных условиях инвестиционная деятельность является одной из предпосылок устойчивого и эффективного развития экономики. Развитие инвестиционной деятельности обеспечивает сочиально-экономические развитие как страны в челом, так и ее регионов. Обстоятельствами, обусловливающими необходимость осущестьления инвестиций, являются обновление имеющейся материально-технической базы, нарацивание объемов производства, развитие инноваций. Инвестиционная привлекательность региона представляет собой систему или сочетание различныхх объективных признаков, средств, возножностей, обусловливаюиих в совокупности потенциальный платежеспособный спрос на инвестиции в данный регион.

Ключевые слова: инфраструктура региона, сочиально-ориентированнал инфраструктура, экономика региона.

Andrey Sysoev

INVESTMENT PROVISION OF DEVELOPMENT OF SOCIAL ORIENTED INFRASTRUCTURE OF THE REGION

In modern conditions, investment activity is one of the prerequisites for sustainable and efficient development of the economy. Investment activity provides the socio-economic development of the country as a whole, and its regions. The circumstances necessitating the need for investment are the renewal of the material and technical base, the increase in production volumes, and the development of innovations. The investment attractiveness of a region is a system or a combination of various possibilities that together determine the potential effective demand for investments in a region.

Key words: infrastructure of the region, socio-oriented infrastructure, regional economy.

Bведение / Introduction. Управление социально ориентированной инфраструктурой региона опирается на решение основных задач социальной политики, направленной на улучшение качества жизни, повышение уровня благосостояния и долголетия населения, а также формирование и воспроизводство здорового, творчески активного и интеллектуально-способного поколения. Параметрами эффективного развития социально ориентированной инфраструктуры региона являются: удовлетворение всесторонних потребностей населения; улучшение условий и качества жизнедеятельности населения, расширение возможностей для формирования и развития человеческого капитала. Достижение заявленных целей невозможно без комплексного инвестиционного обеспечения.

Maтериалы и методы / Materials and methods. Объектом исследования являются процессы инвестиционного обеспечения развития социально ориентированной инфраструктуры региона в контексте современной парадигмы технико-технологического развития. Прикладные исследования и расчеты выполнены преимущественно на примере ряда регионов ЦФО. Информационную основу исследования составили официальные данные Министерства экономического развития РФ, Федеральной службы государственной статистики, публикации в научных изданиях по управлению инновационной деятельностью, программные документы, регламентирующие разработку и реализацию инновационной стратегии развития регионов, оперативная информация о деятельности органов государственной власти РФ, материалы сети Интернет. 
Результаты и обсуждение / Results and discussion. Современное развитие невозможно без активного инвестиционного процесса как на уровне национальной экономики, так и на региональном уровне. Процесс инвестирования играет важную роль в экономике любой страны. Инвестирование в значительной степени определяет экономический рост государства, занятость населения и составляет существенный элемент базы, на которой основывается экономическое развитие общества.

Развитие инвестиционной деятельности обеспечивает социально-экономическое развитие и страны в целом, и ее регионов. Обстоятельствами, обусловливающими необходимость осуществления инвестиций, являются обновление имеющейся материально-технической базы, наращивание объемов производства, а также всестороннее развитие инновационной сферы, которое активизирует процессы создания и освоения новых видов продукции и услуг.

Поскольку в современных условиях инвестиционная деятельность является одной из предпосылок устойчивого и эффективного развития экономики, то большую актуальность приобретает обеспечение привлекательности той или иной территории для потенциальных инвесторов. Для России, которая является крупным федеративным государством, оценка инвестиционной привлекательности отдельных территорий является важным индикатором темпов и уровня их развития.

Инвестиционная привлекательность региона представляет собой систему или сочетание различных объективных признаков, средств, возможностей, обусловливающих потенциальный платежеспособный спрос на инвестиции в данный регион. Инвестиционная привлекательность региона является обобщенной характеристикой, позволяющей исследовать совокупность социальных, экономических, организационных, правовых, политических, социокультурных факторов, мотивирующих инвестора вкладывать ресурсы в развитие экономики региона.

У аналитиков не вызывает сомнений необходимость полноценной и регулярной оценки инвестиционной привлекательности, которая осуществляется независимыми консалтинговыми фирмами, рейтинговыми агентствами, банками, государственными органами $[2,3]$. На практике используется значительное количество методологических подходов к оценке, которые базируются на взаимосвязанной характеристике целого набора факторов. При этом учитываются как макроэкономические показатели (ВВП, ВРП, уровень инфляции), так и географическое положение региона, уровень его обеспеченности природно-сырьевыми ресурсами, степень развития инфраструктуры, кредитно-денежной системы и др.

Многие специалисты отдают предпочтение балльным, преимущественно экспертным, методам оценки, примером которой служит методика, разработанная рейтинговым агентством «Эксперт» [5]. Интегральным показателем оценки инвестиционной привлекательности в данной методике выступает инвестиционный климат, в качестве составляющих которого аналитики агентства «Эксперт» используют две относительно самостоятельные характеристики: инвестиционный потенциал и инвестиционный риск.

Инвестиционная привлекательность региона определяется экономическими, финансовыми, социальными, политическими, информационными, экологическими показателями, демонстрирующими степень его развития в той или иной области, а также положительными прогнозами на будущий период. Исходя из указанных базисных составляющих, на основании статистических данных определены темпы роста инвестиционной привлекательности регионов ЦФО за 20142016 гг. (таблица 1).

Таблича 1

Ранговое распределение регионов ЦФО по темпам роста показателей инвестиционной привлекательности региона

\begin{tabular}{|l|c|c|c|c|c|}
\hline \multirow{2}{*}{ Регион (область) } & $\begin{array}{c}\text { ВРП на душу } \\
\text { населеншя }\end{array}$ & $\begin{array}{c}\text { Объем } \\
\text { инвестищй }\end{array}$ & $\begin{array}{c}\text { Индекс } \\
\text { промьшленного } \\
\text { производства }\end{array}$ & $\begin{array}{c}\text { Среднедушевой } \\
\text { доход населенця } \\
\text { бееработицы }\end{array}$ \\
\hline Белгородская & 10 & 3 & 7 & 3 & 2 \\
\hline Брянская & 8 & 8 & 5 & 11 \\
\hline
\end{tabular}




\begin{tabular}{|c|c|c|c|c|c|}
\hline Регион (область) & $\begin{array}{c}\text { ВРП на душу } \\
\text { населеншя }\end{array}$ & $\begin{array}{c}\text { Объем } \\
\text { инвестищий }\end{array}$ & $\begin{array}{c}\text { Индекс } \\
\text { промьшленного } \\
\text { производства }\end{array}$ & $\begin{array}{l}\text { Среднедушевой } \\
\text { доход населения }\end{array}$ & $\begin{array}{c}\text { Уровень } \\
\text { безработищы }\end{array}$ \\
\hline Владимирская & 5 & 12 & 15 & 17 & 11 \\
\hline Воронежская & 11 & 5 & 14 & 10 & 2 \\
\hline Ивановская & 7 & 17 & 1 & 7 & 11 \\
\hline Калужская & 14 & 15 & 6 & 12 & 2 \\
\hline Костромская & 17 & 11 & 8 & 1 & 10 \\
\hline Курская & 3 & 1 & 13 & 16 & 6 \\
\hline Липецкая & 9 & 2 & 11 & 13 & 4 \\
\hline Московская & 2 & 10 & 2 & 9 & 8 \\
\hline Орловская & 4 & 14 & 17 & 5 & 9 \\
\hline Рязанская & 13 & 16 & 12 & 15 & 2 \\
\hline Смоленская & 15 & 7 & 9 & 14 & 7 \\
\hline Тамбовская & 16 & 13 & 16 & 6 & 3 \\
\hline Тверская & 12 & 6 & 3 & 8 & 5 \\
\hline Тульская & 1 & 4 & 4 & 2 & 2 \\
\hline Ярославская & 6 & 9 & 10 & 4 & 12 \\
\hline
\end{tabular}

В целом по ЦФО наблюдается положительная тенденция роста показателей инвестиционной привлекательности, это заметно по показателю ВРП. Наименьшие темпы роста соответствуют показателям индекса промышленного производства и объема инвестиций. Данный факт можно связать с кризисом 2014 года, когда сократилось производство и инвестиции, ухудшились экономические показатели.

Так, темп роста ВРП Курской области за 2014-2016 гг. составляет 121,87 \%. По большинству показателей наблюдается положительная динамика, за исключением индекса промышленного производства, который после кризиса 2014 года снизился на 0,85 \%. Также отмечается рост безработицы.

В Орловской области также растет уровень безработицы. Кроме того, уменьшился объем инвестиций и индекс промышленного производства. Но, как и в остальных субъектах ЦФО, наблюдается положительная динамика по показателю ВРП на душу населения.

Нами проведено ранговое распределение регионов ЦФО по темпам роста показателей инвестиционной привлекательности. Значения регионов находятся в диапазоне от 1 до 17, что соответствует их количеству (Москва в рейтинге не учитывается). Ранг 1 соответствует максимальному приросту, 17 - минимальному, за исключением уровня безработицы (1 - минимальный прирост, 17 - максимальный).

Тульская область является лидером по темпу роста ВРП, а также занимает в списке лидирующие позиции по изменению таких показателей как: объем инвестиций, индекс промышленного производства и среднедушевой доход. Максимальные темпы роста инвестиций отмечены в Курской области, что можно связать с развитием сельского хозяйства в регионе.

Расчеты показывают, что регионы с высоким уровнем развития имеют суммарные баллы от 13 до 29; регионы со средним уровнем развития имеют суммарные баллы от 29 до 45; регионы с низким уровнем развития имеют суммарные баллы от 45 до 60 . По итогу вычислений составлен рейтинг регионов ЦФО по уровню инвестиционной привлекательности (таблица 2). 
Таблица 2

Распределение регионов ЦФО по уровню инвестиционной привлекательности

\begin{tabular}{|c|c|c|c|c|c|}
\hline \multicolumn{2}{|c|}{ Высокий уровень } & \multicolumn{2}{|c|}{ Средний уровень } & \multicolumn{2}{|c|}{ Низкий уровень } \\
\hline Регион & $\begin{array}{l}\text { Сумма } \\
\text { балов }\end{array}$ & Регион & $\begin{array}{l}\text { Сумма } \\
\text { балов }\end{array}$ & Регион & $\begin{array}{c}\text { Сумма } \\
\text { балов }\end{array}$ \\
\hline Тульская & 13 & Московская & 31 & Костромская & 47 \\
\hline \multirow[t]{7}{*}{ Белгородская } & \multirow[t]{7}{*}{25} & Брянская & 33 & Калужская & 49 \\
\hline & & Тверская & 34 & Орловская & 49 \\
\hline & & Курская & 39 & Смоленская & 52 \\
\hline & & Липецкая & 39 & Тамбовская & 54 \\
\hline & & Ярославская & 41 & Рязанская & 58 \\
\hline & & Воронежская & 42 & \multirow[t]{2}{*}{ Владимирская } & \multirow[t]{2}{*}{60} \\
\hline & & Ивановская & 43 & & \\
\hline
\end{tabular}

Центральный федеральный округ является инвестиционно привлекательным, здесь сосредоточена основная доля производственного потенциала и квалифицированных специалистов. С точки зрения инвестиционной привлекательности предприятия ЦФО являются наиболее перспективными, что также влияет на их потенциал, который, как видно в исследовании, по большинству показателей растет.

Ученые отмечают, что основным средством успешной адаптации экономической системы к неопределенным и быстро изменяющимся условиям среды является эффективный механизм управления, обеспечивающий формирование и реализацию варианта развития, который дает наилучшие в сложившейся ситуации конечные результаты $[1,4]$.

Важным управленческим аспектом является формирование совокупности инструментов и методов, позволяющих региональным органам власти активизировать инвестиционную деятельность (см. рис.).

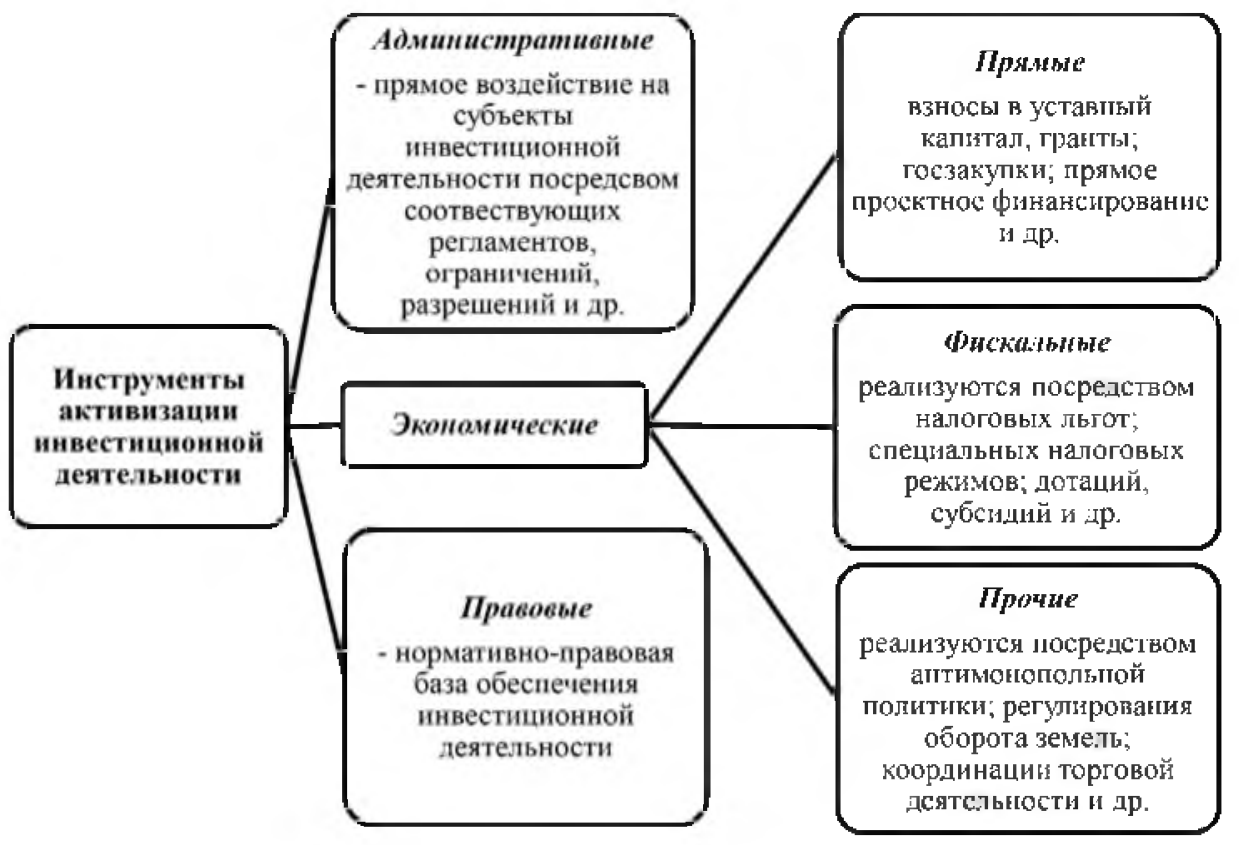

Рис. Инструменты активизации инвестиционной деятельности в регионе 
Региональная инвестиционная политика представляет собой систему мер, направленных на эффективное и полное использование инвестиционного потенциала региона с учетом его специфических особенностей.

Важное место в формировании инвестиционной политики как на уровне региона, так и в рамках национальной экономики отводится учету отраслевой специфики хозяйствующих суб̋ъектов. Она должна разрабатываться на уровне отдельных межотраслевых комплексов и отраслей экономики.

Серьезный прогресс в формировании инновационной экономики может быть достигнут на основе реализации крупномасштабных наукоемких проектов, нацеленных на реализацию критических технологий. Такие проекты требуют привлечения значительных инвестиций при условии гарантий их окупаемости. Это означает, что формируемые отраслевые проекты должны быть ориентированы на получение конкретных практических результатов, производство высокотехнологичной конкурентоспособной продукции и, таким образом, быть максимально привлекательными для инвесторов.

Выполнение этих проектов должно гарантировать крупные сдвиги в технологическом преобразовании отечественного производства, увеличение выпуска конкурентоспособной продукции российскими предприятиями на внутреннем и мировом рынке, решение острых социальных проблем, т. е. в полной мере ориентироваться на реализацию национальных приоритетов. Таким образом, необходимо создать условия, при которых реализация проектов будет выгодна потенциальным инвесторам и одновременно способствовать достижению приоритетных целей развития национальной экономики в целом, и региональной, в частности.

Заключение / Conclusion. Одной из основных задач развития современного общества является создание необходимых и благоприятных условий для усиления инвестиционной привлекательности как государства в целом, так и отдельных регионов в частности. В результате одним из важнейших условий обеспечения устойчивого развития экономики регионов в современных условиях является процесс привлечения отечественных и иностранных инвестиций. Инвестиционная привлекательность зависит от положительного инвестиционного климата в России, правового регулирования инвестиционной деятельности, действенного механизма реализации прав и защиты интересов инвесторов. Активная экспансия России в мировую инвестиционную систему обусловливает не только развитие приоритетных отраслей, развитие социальной сферы, но и направлена на рост инновационности национальной экономики.

\section{ЛИТЕРАТУРА И ИНТЕРНЕТ-РЕСУРСЫ}

1. Емельянов С. Г. Управление развитием высокотехнологичных секторов в формировании воспроизводственных контуров инновационной экономики / С. Г. Емельянов, Е. В. Харченко, Л. В. Широкова, Е. А. Алпеева, Э. В. Ситникова, Д. И. Галахов, Т. С. Колмыкова: монография. Курск, 2013.

2. Колмыкова Т. С., Артемьев О. Г. Инновационные аспекты формирования и развития высокотехнологичного сектора национальной экономики // Вестник Северо-Кавказского федерального университета. 2017. № 1 (58). С. 44-47.

3. Колмыкова Т. С., Астапенко Е. О. Современные аспекты оценки инновационного потенциала региона // Регион: системы, экономика, управление. 2017. № 2 (37). С. 48-52.

4. Мерзлякова Е. А., Колмыкова Т. С., Гончаров А. Ю. Проблемы формирования перспективных точек роста высокотехнологичных производств // Известия Юго-Западного государственного университета. Серия: Экономика. Социология. Менеджмент. 2017. Т. 7. № 3 (24). С. 37-44.

5. Рейтинговое агентство «Эксперт». URL: https://raexpert.ru/

\section{REFERENCES AND INTERNET RESOURCES}

1. Emel'yanovS.G.Upravlenierazvitiemvysokotekhnologichnyhsektorovvformirovaniivosproizvodstvennyh konturov innovacionnoj ekonomiki (Management of the development of high-tech sectors in the formation of the reproductive contours of the innovation economy) / S. G. Emel'yanov, E. V. Harchenko, L. V. Shirokova, E. A. Alpeeva, E. V. Sitnikova, D. I. Galahov, T. S. Kolmykova: monografiya. Kursk, 2013. 
2. Kolmykova T. S.,Artem'ev O. G. Innovacionnye aspekty formirovaniya i raz-vitiya vysokotekhnologichnogo sektora nacional'noj ekonomiki (Innovative aspects of formation and development of high-tech sector of the national economy) // Vestnik Severo-Kavkazskogo federal'nogo universiteta. 2017. № 1 (58). S. 44-47.

3. Kolmykova T. S., Astapenko E. O. Sovremennye aspekty ocenki innovacionnogo potenciala regiona (Modern aspects of evaluation of innovative potential of the region) // Region: sistemy, ekonomika, upravlenie. 2017. № 2 (37). S. 48-52.

4. Merzlyakova E. A., Kolmykova T. S., Goncharov A. Yu. Problemy formirovaniya perspektivnyh tochek rosta vysokotekhnologichnyh proizvodstv (Problems of formation of perspective points of growth of high-tech industries) // Izvestiya Yugo-Zapadnogo gosudarstvennogo universiteta. Seriya: Ekonomika. Sociologiya. Menedzhment. 2017. T. 7. № 3 (24). S. 37-44.

5. Rejtingovoe agentstvo «Ekspert» (Rating Agency "Expert»). URL: https://raexpert.ru/

\section{СВЕДЕНИЯ ОБ АВТОРЕ}

Сысоев Андрей Валерьевич, аспирант, Юго-Западный государственный университет, г. Курск. E-mail: kgtu_ fk@list.ru

\section{INFORMATION ABOUT AUTHOR}

Andrey Sysoev, post-graduate student, southwest state University, Kursk. E-mail:kgtu_fk@list.ru 